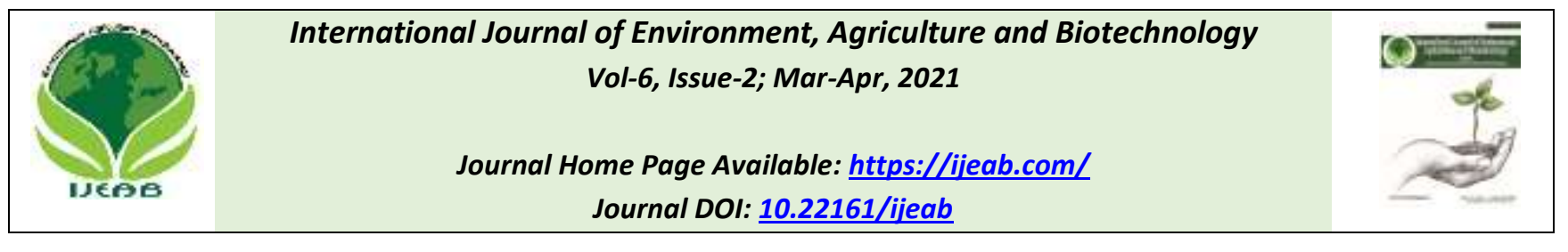

\title{
Observation of El Niño and La Niña Phenomena, on the island of Sulawesi - Indonesia, based on the Global Positioning System (GPS)
}

\author{
Syachrul Arief
}

Geospatial Information Agency Indonesia - Jl. Raya Bogor KM. 46 Cibinong 16911

Received: 05 Dec 2020; Received in revised form: 11 Feb 2021; Accepted: 19 Mar 2021; Available online: 16 Apr 2021

C2021 The Author(s). Published by Infogain Publication. This is an open access article under the CC BY license

(https://creativecommons.org/licenses/by/4.0/).

\begin{abstract}
This paper studies precipitable water vapor (PWV) in 2015-2016, an El Niño-Southern Oscillation episode (ENSO), and causes drought in Indonesia. Using the Global Positioning System (GPS), we obtained the $P W V$ value. Expected can detect ENSO phenomenon through PWV value. We processed the GPS observation data by Precise Point Positioning (PPP) method using the goGPS software. The obtained values of Zenith Troposphere Delay (ZTD) and PWV were validated by comparing with the ZTD values from four IGS stations (BAKO, PIMO, NTUS, ALIC), i.e., there was a mean difference of -3.48 , the average standard deviation is 13.36 $\mathrm{mm}$, and the correlation coefficient was 0.94. The variation between the IGS ZTD and PPP ZTD estimates is within the measurement error. Our results can be used to study PWV behaviors for meteorological and climatological purposes in Indonesia. The values of PWV obtained from station GPS CMAK and CBIT were compared with $P W V$ by radiosonde observations. The results showed a good agreement with the coefficient correlation is 0.86 at CMAK Station and 0.85 at CBIT station. The PWV values at CBIT stations varied between 37.08 and $76.01 \mathrm{~mm}$ with an average of $57.05 \mathrm{~mm}$. For CTOL, CMAK, and CKEN stations, their average PWV is 61.17, 50.84, and $51.75 \mathrm{~mm}$. The standard deviation (STD) value of the PWV at CMAK stations was 11.79 mm, higher than the other stations. During the El Niño event, the correlation between SSTa and PWV became weak at the four stations.
\end{abstract}

Keywords-PWV, ENSO, GPS, PPP, ZTD, SULAWESI.

\section{INTRODUCTION}

The Global Positioning System is the oldest Global Navigation Satellite Systems (GNSS). Indonesia's GPS network has been used only for positioning, surveying, and mappings, such as inland administration, mining, and transportation sectors. It has not been utilized to observe the Earth's atmosphere, including meteorological and climatological studies. In the early 90s, (Bevis et al. 1992) first proposed GPS meteorology, i.e., we can use ground GPS stations to study water vapor behaviors in the lower atmosphere (the troposphere) called precipitable water vapor (PWV).

PWV is an important parameter that has an essential role in weather and global climate. One of the factors influencing climate change is the ENSO phenomenon, El
Niño, Southern Oscillation, and the phenomenon opposite ENSO (LaNiña). We used the four indicators to detect the ENSO phenomenon, the sea surface temperature anomaly (SSTa), sea surface pressure anomaly (SLPa), and multivariate ENSO index (MEI), and rainfall gradient (Curtis and Adler 2000).

This study investigates the behavior of PWV in 20152016. Based on data from the National Oceanic and Atmospheric Administration (NOAA), El Niño in 20152016 was more robust than El Niño in 1997-1998. During El Niño, many parts of Indonesia experience drought. We address the question of whether GPS-PWV can detect ElNiño, especially when El Niño grows and decays. These techniques are cost-effective because we use pre-existing infrastructure, the GNSS network in Indonesia. In this 
research, we will focus on ENSO analysis, especially El Niño, by GPS PWV monitoring on the island of Sulawesi.

\section{DATA DAN METHOD}

\section{PWV Retrieved from GPS}

The measurement concept of PWV with GPS is illustrated in figure 1. In the model, a microwave signal propagates from the GPS satellite to the receiver on the ground, which deforms with the seawater's loading mechanisms. GPS signals that propagate through the Earth's atmosphere suffer from the variability of the ionosphere's refractive index and troposphere. Delays are caused by two factors, i.e., the excess path caused by the bending of the microwave path and the delay along the way caused by the refractive index (Suparta 2012). The tropospheric zenith total delay (ZTD) consists of zenith hydrostatic delay (ZHD) and zenith wet delay (ZWD). ZWD can be calculated based on the Hopfield model [H. Hopfield, 1969]. ZHD can be calculated using the Saastamoinen model (Saastamoinen, 1972).We used the Vienna mapping functions (VMF1) to convert zenith delays to those along the line-of-sight (Suparta et al., 2011).ZWD is calculated by subtracting ZHD from ZTD. ZWD was later transformed into approximate PWV (in $\mathrm{mm}$ ) by employing the surface temperature measured at a particular site. To calculate the PWV, we need meteorological data, such as pressure $(\mathrm{P})$, temperature $(\mathrm{T})$, and relative humidity $(\mathrm{H})$. Meteorological data are obtained by meteorological sensors installed on the GPS Stations to get the accurate PWV.

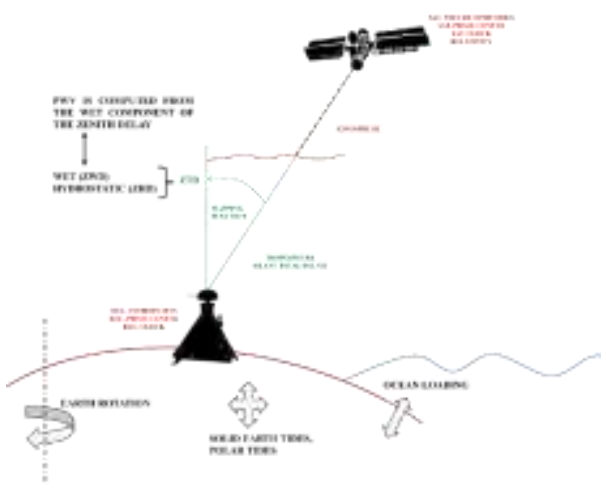

Fig. 1 Propagation of GPS signals to a receiver on the ground that covers the sea surface temperature influences

The conversion from ZWD to PWV is done using the formula by (Bevis et al. 1992),

$\mathrm{PWV}=\pi(\mathrm{Tm}) \mathrm{ZWD}$
Where $\pi(\mathrm{Tm})$ is the conversion factor that varies with the local climate and depends on weighted mean temperature (Tm, in Kelvin).

$\mathrm{Tm}=0.83663 \mathrm{Ts}+48.103$

Where Ts is the surface temperature (in Kelvin), note that the Tm equation (2) was obtained empirically by linear regression for 15 selected radiosonde stations over the Western Pacific (Bevis et al. 1992)

\section{Dataset}

GPS data for the meteorological study were collected from the four stations in Sulawesi Island, Indonesia. We selected the El Niño episode that occurred in 2015/2016. We processed the data to study the response of PWV to ENSO. The four GPS stations are Makasar (CMAK), Kendari (CKEN), Toli-Toli (CTOL), and Bitung (CBIT) observatories. Data from the meteorological sensors were used for the individual GPS stations. All GPS stations recorded the carrier phase with an interval of 30 seconds. The stations are shown in Fig. 2. To link the activities of ENSO with PWV response, SSTa Oceanic

Niño Index (ONI) on the Niño 3.4 area was obtained daily from the National Oceanic and Atmospheric Administration (NOAA).

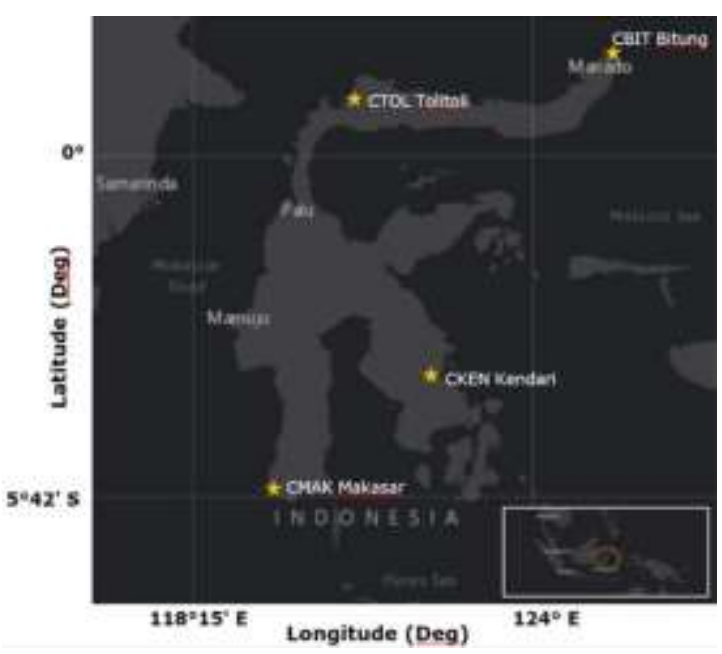

Fig. 2 Location 4 station for study

\section{Data Processing}

Ground-based GPS data can be processed to determine ZTD in two different ways : (1) Baseline network solution using double-difference observable (Bevis et al. 1992) and (2) Precise Point Positioning (PPP) using indifference observable (Byun and Bar-Sever 2009).

The baseline approach is the most commonly used in GPS processing. It is done with two or more receivers 
simultaneously observing GPS satellites. This technique provides precise ZTD estimates, but the separation distance between adjacent receivers limits its effectiveness. On the other hand, PPP can be performed for a set of single GPS receivers to estimate the precise values of ZTD. It should be emphasized that in PPP, precise satellite orbit and clock correction data are needed.

In this research, the ZTD results derived using PPP processing methods were compared and evaluated with the ZTD from the International GNSS Service (IGS) final troposphere. One week of GPS observations was collected from 4 IGS network stations, i.e., BAKO, NTUS, PIMO, ALIC. This validates that the methods we used to calculate the PWV in subsequent studies. For more information on the IGS final troposphere product, refer to http://igscb.jpl.nasa.gov/.

To process and analyze the data signal and GPS meteorology in RINEX format, we used the software package goGPS in the PPP model. goGPS is an opensource software application developed by (Realini et al. 2012) since 2007 at Geomatics Laboratory of the Politecnico di Milano, Como Campus. Initially, it was created in MATLAB but was recently converted to Java to expand its users. They started to provide it as a service through the web.

To validate the PWV values from GPS, we compared them with those from radiosonde observations around the GPS stations we used. Radiosondes provide various quantities concerning the atmosphere, including temperature, pressure, and humidity. They are often used in validating GPS-PWV data as a reliable source of independent data. Although radiosondes provide meteorological observations with a high vertical resolution, their temporal and spatial resolutions are not high. Therefore, we compare GPSPWV values observed at times when the radiosondes are released. The PWV from radiosondes is considered to be accurate to $\sim 1.2 \mathrm{~mm}$ (Feng, Bai, and Williams 2001)

In this study, we used two radiosonde sites on Sulawesi Island operated by the Indonesia Agency of Meteorology, Climatology, and Geophysics. They were found to be close to two of the GNSS stations used in this study. These stations located at the Sultan Hasanudin Airport in Makasar (WAAA) and the Sam Ratulangi Airport near Bitung (WAAM). The nearest GNSS stations to these radiosonde sites are Makasar Observatory (CMAK) and Bitung (CBIT).

\section{RESULTS AND DISCUSSION}

\section{Troposphere Zenith Delay}

The mean, standard deviation, and the correlation between the ZTD estimate obtained from goGPS software with PPP processing and ZTD from IGS for the stations over one week are listed in Table 1. The mean difference between the two processing methods is more petite than $-3.48 \mathrm{~mm}$. The mean, standard deviation is $13.36 \mathrm{~mm}$, and the mean correlation is 0.89 . This shows good agreement results in ZTD goGPS with ZTD from IGS.

Table 1 Statistical compilation ZTD processing by goGPS software and ZTD from IGS

\begin{tabular}{|l|c|c|c|}
\hline \multicolumn{1}{|c|}{ Station ID } & Diff $(\mathrm{mm})$ & STD $(\mathrm{mm})$ & Correlation \\
\hline BAKO & -3.77 & 13.58 & 0.87 \\
\hline PIMO & -6.47 & 13.60 & 0.95 \\
\hline NTUS & -3.28 & 13.06 & 0.76 \\
\hline ALIC & -0.40 & 13.20 & 0.99 \\
\hline Average & -3.48 & 13.36 & 0.89 \\
\hline & \multicolumn{3}{|c|}{} \\
\hline \\
\hline
\end{tabular}

Fig. 3 One-week comparison between the IGS final tropospheric product with PPP processing solutions at BAKO GPS station

The ZTD estimates for the BAKO station from the IGS and our solution are compared in Fig. 3. The results from both are consistent, and the deviations between the two solutions are well within the level of $1-2 \mathrm{~cm}$. These results conform to the findings in (Bevis et al. 1992),(Gao and Chen 2004), (Gendt, Reigber, and Dick 2001), and (Rocken et al. 1993). An error of 1-2 cm in ZTD equals an error of 1-3 $\mathrm{mm}$ in PWV, which is considered insignificant for this study. Therefore, we use this PPP solution in the following analysis, unless stated otherwise.

\section{Validation of ground-based GPS-PWV with radiosondes.}

One-month of GPS-PWV estimates at these stations were calculated using measurements from the nearest weather stations. The GPS-PWV and radiosonde-PWV time series at these stations are illustrated in Fig. 4

The correlation coefficient shows good agreement between the two data sets, particularly at the CMAK-WAAA station pair. The GPS receiver and radiosonde station are collocated. We use these PWV values to study the link 
between PWV and climate changes, e.g., the El Niño episodes.

\section{PWV and SSTa Variability}

Figure 5 shows the variation of daily averages of the PWV from GPS measurements in 2015/2016 at four selected CBIT, CTOL, CMAK, and CKEN. This figure shows that the PWV at the four stations shows different patterns. At the CBIT station, PWV varies between 37.08 and 76.01 $\mathrm{mm}$, with an average of $57.05 \mathrm{~mm}$. For stations CTOL, CMAK, and CKEN, their average PWV is 61.17, 50.84, and $51.75 \mathrm{~mm}$, respectively. The standard deviation (STD) of the PWV at the CMAK station, $11.79 \mathrm{~mm}$, was higher than other stations.

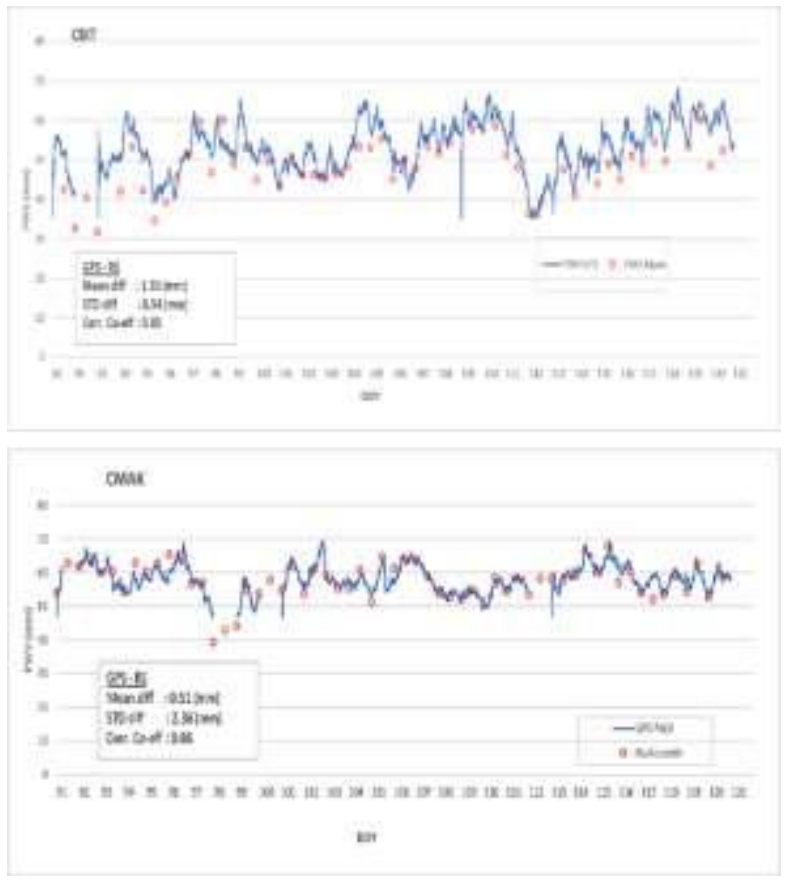

Fig. 4 Comparison between the GPS-PWV (solid line) and radiosonde-PWV for CBIT (upper) and CMAK (lower) stations, respectively. The red circles show radiosonde estimates of water vapor.

From Figure 5, PWV at CMAK and CKEN stations show a clear pattern that PWV values are higher during the rainy season (Oct-Mar) and lower during the dry season (AprSept). This tendency was also seen at the CBIT and CTOL stations, but there was not so strong. The PWV at CBIT and CTOL increase during April-May 2016. Significant PWV fluctuation occurred during 2015 at the CMAK and CKEN stations in July when ENSO activity disturbed the two stations' atmosphere.

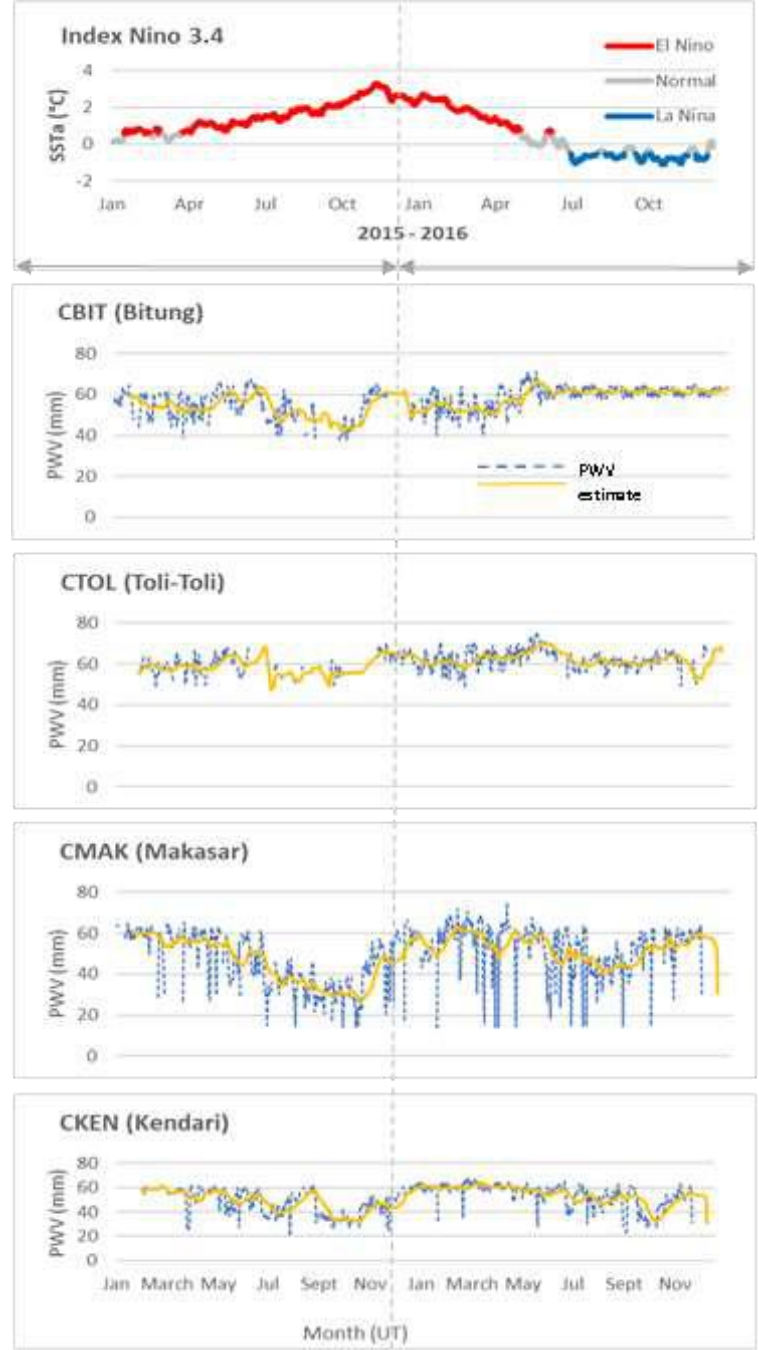

Fig. 5 The daily average of $P W V$ variation from GPS measurements during 2015 and 2016

Intense ENSO episodes were recorded in 1982/83, 1997/1998, and 2015/2016. Such ENSO episodes play an essential role in generating extreme conditions in the Pacific Ocean and the region around Sulawesi. There are two approaches to identify the occurrence of ENSO. In the first definition, an ENSO event is considered to occur when the 5-month running average of the SST anomaly (SSTa) in the Niño 3.4 region is above 0.4 degrees for six months (Trenberth 1997). As the second definition, the Japan Meteorological Agency (JMA) uses the oceanic of Niño 3 (4N-4S and 150-90W). They consider it an ENSO event when the 5-month running average of the SST in this area (SSTa) exceeds the thresholds of 0.5 degrees or more for six consecutive months (Bove et al. 1998). 
(a)

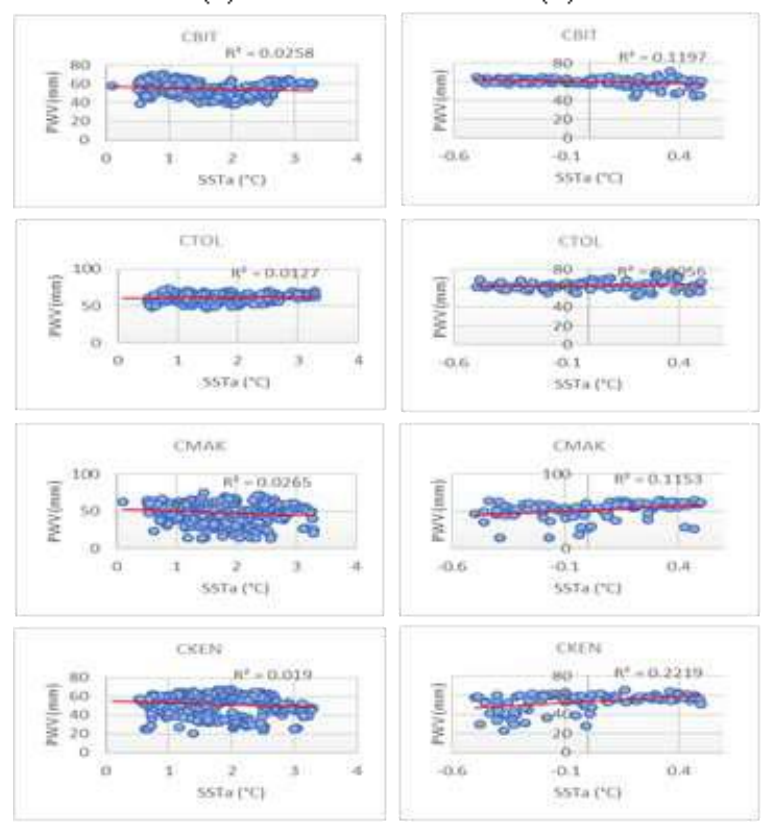

Fig. 6 Scatter plot between GPS PWV and SSTa for Index Niño 3.4 region for the year of 2015/2016

Figure 5 shows the identification of ENSO, according to NOAA, based on the first definition. The period of more than 12 months shown in red Five to an El Niño episode (SSTa $>0,5)$, while the part is shown in blue (SSTa $<-0.5)$, is a La Niña event. The gray color part is neutral. From this figure, the El Niño event was from the middle of January from 2015 to May 2016. Its peak is around November 2015, where the SSTa anomaly in the Niño 3.4 region is 3.28 degrees.

\section{Monitoring of PWV Variability from GPS During El Niño Event}

The correlation analysis was done to show PWV responses to El Niño events, i.e., we compare the PWV values among the periods of El Niño, neutral, and La Niña. During the El Niño episode, its intensity (ENSO index) varies in time. We also analyze the PWV changes associated with the difference in the index. The responses seem to go among the four stations.

Table 2 The correlation coefficient between GPS PWV and SSTa during the El Niño event for the case of 2015/2016

\begin{tabular}{|c|c|c|c|}
\hline Station (City) & Niño 3.4 & Normal & LaNiña 3.4 \\
\hline CBIT (Bitung) & -0.1606 & -0.3460 & -0.1469 \\
\hline CTOL (Toli-toli) & 0.1126 & 0.0748 & 0.0882 \\
\hline CMAK (Makasar) & -0.1627 & 0.3395 & -0.2384 \\
\hline CKEN (Kendari) & -0.1378 & 0.4710 & -0.0579 \\
\hline Average & -0.0871 & 0.1348 & -0.0887 \\
\hline
\end{tabular}

Below is the classification of correlation coefficients,

1. 0. "no correlation."

2. $0.20-0.39$ "weak."

ISSN: 2456-1878

https://dx.doi.org/10.22161/ijeab.62.11
3. $0.40-0.59$ "moderate"

4. $0.60-0.79$ "strong."

5. $0.80-1.0$ "very strong"

During the El Niño episode shown in Figure .6a., the correlation between SSTa and PWV is very weak at four stations, i.e., below 0.20. For neutral conditions (Figure $6 b)$. The correlation between SSTa and PWV is weak at CBIT, very weak at CTOL, soft at CMAK, and moderate at CKEN (0.4710). During LaNiña, a weak correlation is found only at Makasar station (CMAK). It is very weak at the other three stations.

The weak response to El Niño at these sites may be due to seasonal changes from the rainy season to the dry season. The relationship between PWV from GPS and SSTa for Niño 3.4 did not show any significant correlation, either.

During the El Niño intensity increase in April-November 2015 (Figure 7a). Of the four existing stations, a correlation between GPS PWV and SSTa is very weak at CBIT, weak at CTOL, moderate at CMAK, and soft at CKEN. The overall average correlation is very weak.
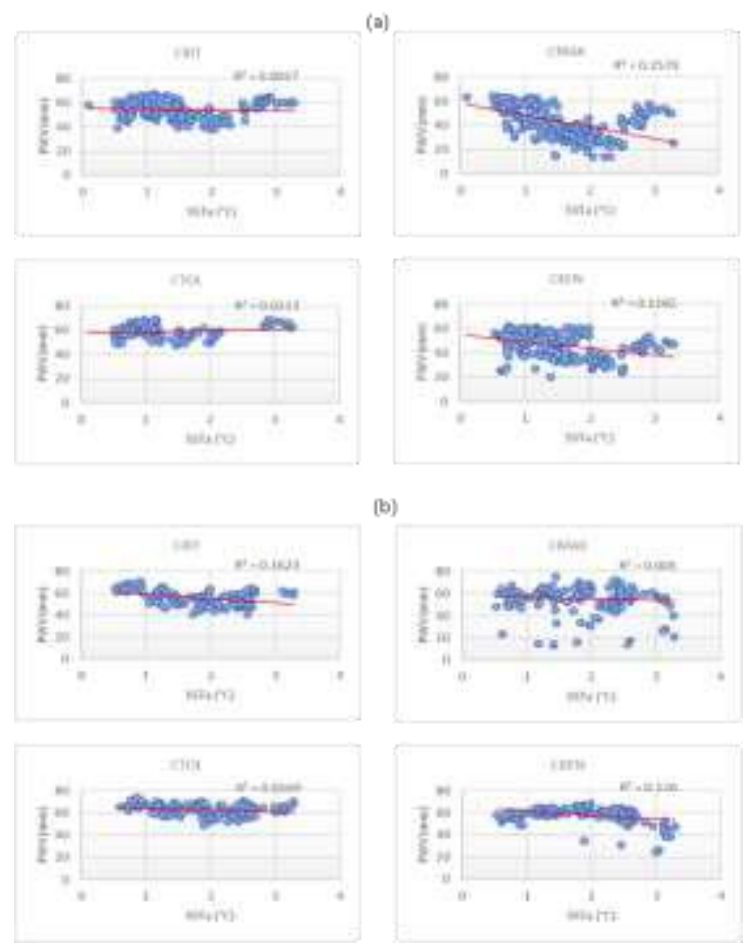

Fig. 7 Scatterplot between GPS PWV and SSTa from Niño 3.4region during El Niño event for 2015/2016 (a) the decreased intensity and $(b)$ the increasing intensity. 


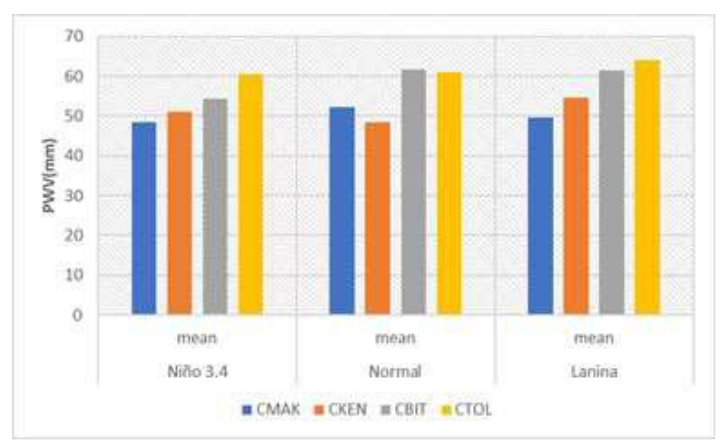

Fig. 8 Graph of average PWV value under El Niño condition, neutral condition, and LaNiña, at four stations in 2015/2016

On the other hand, decreasing the ENSO index in November 2015-June 2016 (Figure 7b) shows a moderate correlation with GPS PWV at CBIT, the weak correlation at CTOL, the very weak correlation at CMAK, and CKEN. The overall average correction between the declining El Niño intensity and PWV is soft.

Figure 8 shows that the average PWV during LaNiña is generally higher than in El Niño and Neutral conditions at all four stations. More statistics details are given in Table 2. However, further and more in-depth research is needed to address the response of PWV to ENSO.

\section{CONCLUSIONS}

We studied the variability of GPS-PWV and SSTa during the 2015/2016 period covering El Niño, neutral. La Niña episodes using data from four stations in Sulawesi, Indonesia, i.e., CBIT, CTOL, CMAK, and CKEN. The GPS-PWV and SSTa showed a negative correlation. The decrease in PWV also correlates with the dry season lasting from April to September, when water vapor in the atmosphere offers a minimum. The selected GPS receivers in the Sulawesi region may not be optimal for studying PWV changes by ENSO since the correlation between PWV and SSTa was weak throughout the period. Nevertheless, by comparing the average PWV values in the El Niño, neutral, and La Niña conditions, We could show that average PWV offers smaller deals in the El Niño period than in the La Niña period. Further research is needed to find out more details.

\section{ACKNOWLEDGEMENTS}

We want to thank RISET-Pro Kemenristekdikti, Geospatial Information Agency — Indonesia, for providing GNSS data within the limited-term. IGS data are available from the web (ftp://garner.ucsd.edu/).

\section{REFERENCES}

[1] Bevis, M, S Businger, T A Herring, C Rocken, R A Anthes, and R H Ware. 1992. "GPS Meteorology: Remote Sensing of Atmospheric Water Vapor Using the Global Positioning System.” Journal of Geophysical Research.

[2] Bove, Mark C., James B. Elsner, Chris W. Landsea, Xufeng Niu, and James J. O’Brien. 1998. "Effect of El Niño on U.S. Landfalling Hurricanes, Revisited." Bulletin of the American Meteorological Society 79 (11): 2477-82. https://doi.org/10.1175/15200477(1998)079<2477:EOENOO>2.0.CO;2

[3] Byun, Sung H., and Yoaz E. Bar-Sever. 2009. "A New Type of Troposphere Zenith Path Delay Product of the International GNSS Service." Journal of Geodesy 83 (3-4): 367-73. https://doi.org/10.1007/s00190-008-0288-8.

[4] Curtis, S., and R. Adler. 2000. "ENSO Indices Based on Patterns of Satellite-Derived Precipitation." Journal of Climate 13 (15): 2786-93. https://doi.org/10.1175/15200442(2000)013<2786:EIBOPO>2.0.CO;2.

[5] Feng, Yanming, Zhengdong Bai, and Allyson Williams. 2001. "GPS Water Vapour Experimental Results From Observations of the Australian Regional GPS Network ( ARGN )." 2001 - A Spatial Odessy: 42nd Australian SUrveyors Congress, no. May.

[6] Gao, Yang, and Kongzhe Chen. 2004. "Performance Analysis of Precise Point Positioning Using Rea-Time Orbit and Clock Products." Journal of Global Positioning Systems 3 (1\&2): 95-100. https://doi.org/10.5081/jgps.3.1.95.

[7] Gendt, G., C. Reigber, and G. Dick. 2001. "Near Real-Time Water Vapor Estimation in a German GPS Network-First Results from the Ground Program of the HGF GASP Project." Physics and Chemistry of the Earth, Part A: Solid Earth and Geodesy 26 (6-8): 413-16. https://doi.org/10.1016/S1464-1895(01)00075-8.

[8] Realini, Eugenio, Daisuke Yoshida, Mirko Reguzzoni, and Venkatesh Raghavan. 2012. "Enhanced Satellite Positioning as a Web Service with GoGPS Open Source Software."

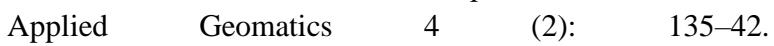
https://doi.org/10.1007/s12518-012-0081-5.

[9] Rocken, Christian, Randolph Ware, Teresa Van Hove, Fredrick Solheim, Chris Alber, James Johnson, Mike Bevis, and Steven Businger. 1993. "Sensing Atmospheric Water Vapor with the Global Positioning System." Geophysical Research Letters. https://doi.org/10.1029/93GL02935.

[10] Saastamoinen. 1972. "National Research Council of Canada," no. 105: 383-97.

[11] Suparta, Wayan. 2012. "The Use of GPS Meteorology for Climate Change Detection." Proceedings of the 2012 International Conference in Green and Ubiquitous Technology, GUT 2012, 71-73. https://doi.org/10.1109/GUT.2012.6344191.

[12] Suparta, Wayan, Mandeep Singh Jit Singh, Mohd Alauddin Mohd. Ali, Baharudin Yatim, and Ahmad Norazhar Mohd Yatim. 2011. "GPS Water Vapor Monitoring and TroWav Updated for ENSO Studies.” Proceedings - International Conference on Instrumentation, Communication, Information Technology, and Biomedical Engineering 2011, 
ICICI-BME 2011, no. November: 35-39. https://doi.org/10.1109/ICICI-BME.2011.6108591.

[13] Trenberth, Kevin E., 1997. "The Definition of El Nino ProQuest." Bulletin of the American Meteorological Society, no. August: 2771-77. https://doi.org/10.1175/15200477(1997)078<2771:TDOENO>2.0.CO;2. 